\title{
Effects of nitrogen, phosphorus and potassium fertilization on photosynthetic characteristics, yield and quality of Pulsatilla chinensis
}

\author{
WEI Qing-cui ${ }^{1}$, LI Cheng-zhong ${ }^{2 *}$ \\ ${ }^{1,2}$ Department of Horticulture and Landscape, Jiangsu Agri-animal Husbandry Vocational College, China \\ *Corresponding Author: LI Cheng-zhong, Department of Horticulture and Landscape, Jiangsu Agri- \\ animal Husbandry Vocational College, China
}

\begin{abstract}
Abs tract: The effects of nitrogen, phosphorus and potassium fertilization on photosynthetic characteristics, yield and quality of Pulsatilla chinensis were studied in order to provide theoretical basis for standardized production of Pulsatilla chinensis. Field experiments were conducted with three factors quadratic saturation and D-optimal design, and photosynthetic parameters, dry matter quality and total saponin content ofleaves were measured. The results showed that Pulsatilla chinensis had the greatest demand for nitrogen fertilizer, phosphate fertilizer had greater influence on photosynthetic characteristics, root growth and quality, and potassium fertilizer had more obvious influence on the growth of aboveground parts. In field cultivation, Pulsatilla should be properly proportioned with comprehensive consideration ofyield and quality. the optimal fertilization scheme is nitrogen $180 \mathrm{~kg} / \mathrm{hm}^{2}$, phosphorus $225 \mathrm{~kg} / \mathrm{hm}^{2}$ and potassium $79.8 \mathrm{~kg} / \mathrm{hm}^{2}$.
\end{abstract}

Keywor ds: Pulsatilla chinensis; Photosynthetic characteristics; Output; Total saponin content

\section{INTRODUCTION}

Pulsatilla chinensis Regel is a perennial herb of Pulsatilla in Ranunculaceae, native to China, distributed in northeast China, north China, east China and other regions, like light, and born in wasteland and wilderness ${ }^{[1]}$. Roots, leaves and flowers of Pulsatilla chinensis can be used as medicines, which belongs to traditional Chinese medicinal materials in China and is mainly effective as saponin ( Pulsatilla saponin $\mathrm{A}_{3}$, Pulsatilla saponin $\amalg$, cephalin $\mathrm{B}_{4}$ ). pharmacological studies show that it has antitumor, anti-parasitic and antioxidant effects ${ }^{[2]}$. At present, the research on Pulsatilla chinensis mostly focuses on chemical composition ${ }^{[3]}$, pharmacological action ${ }^{[4]}$, tissue culture and propagation ${ }^{[5]}$. and seed germination ${ }^{[6]}$, and the research on artificial cultivation technology is still in its infancy, and there are few reports on the research on the high-yield fertilization technology of Pulsatilla chinensis, and fertilization in Pulsatilla chinensis production mostly depends on farmers' experience, resulting in environmental pollution and resource waste. In this study, field experiments were designed with three factors quadratic saturation and D- optimal design, and the effects of nitrogen, phosphorus and potassium formula fertilization on leaf photosynthetic characteristics, dry matter yield and total saponin content of Pulsatilla chinensis in growth stage were analyzed in depth, in order to determine the optimal fertilization amount of nitrogen, phosphorus and potassium, and provide theoretical basis for standardized production of Pulsatilla chinensis.

\section{Materials ANd Methods}

\subsection{General Situation of the Test Site}

The experiment was conducted in the training base of Jiangsu vocational college of agriculture and animal husbandry science and technology ( $3227^{\prime} 42^{\prime \prime} \mathrm{N}, 11955^{\prime} 57^{\prime \prime} \mathrm{E}$ ), located in the middle of Jiangsu province, with an average annual temperature of $14.4^{\circ} \mathrm{C}-15.1{ }^{\circ} \mathrm{C}$; The average annual precipitation is $1037.7 \mathrm{~mm}$, and the rainfall day is $113 \mathrm{D}$. the soil type is sandy soil. the $0-30 \mathrm{~cm}$ plough layer soil contains $23.17 \mathrm{~g} \cdot \mathrm{kg}^{-1}$ organic matter, $92.63 \mathrm{mg} \cdot \mathrm{kg}^{-1}$ alkaline hydrolysis nitrogen, $30.37 \mathrm{mg} \cdot \mathrm{kg}^{-1}$ available phosphorus, $92.34 \mathrm{mg} \cdot \mathrm{kg}^{-1}$ available potassium and $6.86 \mathrm{ph}$.

\subsection{Experimental Mate rials}

Pulsatilla seeds were collected from Liuhe district, Nanjing city, Jiangsu province, China. they were 
Effects of nitrogen, phosphorus and potassium fertilization on photosynthetic characteristics, yield and quality of Pulsatilla chinensis

identified as seeds of Ranunculaceae plants by professor Tang Geng - Guo, Nanjing forestry university. they were sown in the acupuncture points of the training base in Jiangsu vocational college of agriculture and animal husbandry science and technology in early March, 2015. they were planted in the test site in October of the same year. the row spacing of plants was $15 \mathrm{~cm} \times 25 \mathrm{~cm}$, and the plot area was $10 \mathrm{~m} \times 1.5 \mathrm{~m}$. Urea (containing $46 \% \mathrm{~N}$ ) is used as nitrogen fertilizer, superphosphate (containing $14 \% \mathrm{P}_{2} \mathrm{O}_{5}$ ) is used as phosphorus fertilizer, and potassium sulfate (containing $54 \% \mathrm{~K}_{2} \mathrm{O}$ ) is used as potassium fertilizer.

\subsection{Test Design}

This experiment adopts the three-factor quadratic saturation and D - optimal design, selects three kinds of fertilizers, namely nitrogen, phosphorus and potassium, and sets four levels for each fertilizer, CK as the control, and sets 10 treatments in total, and repeats them for three times. see table 1 for specific scheme design. In early April, 2017, all fertilizers were evenly mixed according to the design scheme, furrowing between rows, and top dressing was applied in two times, and other management measures in each community were the same.

Table1. N, $P$ and $K$ three factors quadratic saturation and D - optimal design scheme

\begin{tabular}{|c|c|c|c|c|c|c|c|}
\hline \multirow{2}{*}{$\begin{array}{l}\text { Treatment } \\
\text { number }\end{array}$} & \multicolumn{3}{|c|}{ Fertilizing amount $\left(\mathrm{kg} / \mathrm{hm}^{2}\right)$} & \multirow{2}{*}{$\begin{array}{c}\text { Processing } \\
\text { number }\end{array}$} & \multicolumn{3}{|c|}{ Fertilizing amount0 $\left(\mathrm{kg} / \mathrm{hm}^{2}\right)$} \\
\hline & $\mathrm{N}$ & $\mathrm{P}_{2} \mathrm{O}_{5}$ & $\mathrm{~K}_{2} \mathrm{O}$ & & $\mathrm{N}$ & $\mathrm{P}_{2} \mathrm{O}_{5}$ & $\mathrm{~K}_{2} \mathrm{O}$ \\
\hline 1 & 0 & 0 & 0 & 6 & 107.3 & 0 & 134.2 \\
\hline 2 & 180 & 0 & 0 & 7 & 0 & 134.2 & 134.2 \\
\hline 3 & 0 & 225 & 0 & 8 & 63.8 & 225 & 225 \\
\hline 4 & 0 & 0 & 225 & 9 & 180 & 79.8 & 225 \\
\hline 5 & 107.3 & 134.2 & 0 & 10 & 180 & 225 & 79.8 \\
\hline
\end{tabular}

\subsection{Test methods}

\subsubsection{Determination of Photosynthetic Parameters}

From April to September, 2017, the fully expanded functional leaves ( 3rd to 4th leaves from outside to inside ) were selected in the middle of each month to measure photosynthetic parameters, and on sunny morning ( 9: 00 - 10: 00 ), the fully expanded functional leaves of Pulsatilla with different fertilization treatments were measured by ciras - 2 portable photosynthetic measurement system, including net photosynthetic rate $(P n)$, stomatal conductance $(G S)$, intercellular $\mathrm{CO}_{2}$ concentration $(\mathrm{Ci})$ and transpiration rate $(T r)$. During the determination, the light intensity is about $800 \mu \mathrm{mol} \cdot \mathrm{m}^{-2} \cdot \mathrm{s}^{-1}$, the atmospheric temperature is $\left(25 \pm 1^{\circ} \mathrm{C}\right)$, and the atmospheric $\mathrm{CO}_{2}$ concentration is $400 \pm 10 \mu$ mol.mol ${ }^{-1}$.

\subsubsection{Determination of Dry Matter}

From April to September, 2017, samples were taken in the middle of each month, and 10 plants were randomly selected for each treatment. after cleaning, the above-ground part was separated from the underground part, and the above-ground part was de-enzyme in an oven at $105^{\circ} \mathrm{C}$ for $15 \mathrm{~min}$, and then the underground part was dried to constant weight in an oven at $60{ }^{\circ} \mathrm{C}$ together with the underground part, and the dry matter weight was weighed, and the root-shoot ratio was calculated.

\subsubsection{Determination of Total Saponin Content Pulverizing Dried Roots of Each Treatment}

Sieving with 60 mesh sieve, extracting total saponin by ultrasonic method, and determining total saponin content by vanillin - perchloric acid colorimetry ${ }^{[7]}$. Excel 2013 was used for data processing and tabulation, and DPS 9.50 software was used for variance analysis, significance test (Duncan new complex polar difference method) and correlation analysis.

\section{RES ULTS AND ANALYS IS}

\subsection{Effects of Different Fertilization Treatments on Photos ynthe tic Characteristics of Pulsatilla Chinensis}

As can be seen from table 2, compared with the control (treatment 1), photosynthetic parameters of Pulsatilla chinensis leaves in different treatments increased to different degrees, and the differences were significant or extremely significant. Single application of nitrogen fertilizer, phosphate fertilizer and potash fertilizer promoted the net photosynthetic rate, stomatal conductance, intercellular $\mathrm{CO}_{2}$ concentration and transpiration rate of Pulsatilla chinensis leaves in detail. among them, single application of nitrogen fertilizer promoted the most obvious effect, followed by single application of 
Effects of nitrogen, phosphorus and potassium fertilization on photosynthetic characteristics, yield and quality of Pulsatilla chinensis

phosphate fertilizer, and the difference among them reached significant level. The effects of nitrogen, phosphorus and potassium fertilizers on photosynthetic parameters of Pulsatilla chinensis leaves were as follows: nitrogen-phosphorus combination $>$ nitrogen-potassium combination $>$ phosphoruspotassium combination. In the treatment of nitrogen fertilizer, phosphate fertilizer and potash fertilizer, the promotion effect of stomatal conductance and transpiration rate in treatment 9 was the most obvious, and the promotion effect of net photosynthetic rate and intercellular $\mathrm{CO}_{2}$ concentration in treatment 10 was the most obvious.

Table2. Photosynthetic parameters of different fertilization in Pulsatilla chinensis $(\bar{x} \pm s)$

\begin{tabular}{|c|c|c|c|c|}
\hline Number & $\begin{array}{c}(P n) \\
\text { Photosynthetic rate } \\
\left(\mu \mathrm{mol} . \mathrm{m}^{-2} . \mathrm{s}^{-1}\right)\end{array}$ & $\begin{array}{c}(\mathrm{Gs}) \\
\text { Stomatal conductance } \\
\left(\mu \mathrm{mol} \cdot \mathrm{m}^{-2} . \mathrm{s}^{-1}\right)\end{array}$ & $\begin{array}{c}(\mathrm{Ci}) \\
\text { Intracellular } \mathrm{CO}_{2} \text { concentration } \\
\left(\mu \mathrm{molO}_{2} . \mathrm{m}^{-2} . \mathrm{s}^{-1}\right)\end{array}$ & $\begin{array}{c}(\mathrm{Tr}) \\
\text { Transpiration rate } \\
\left(\mu \mathrm{mol}^{-2} \mathrm{~m}^{-2} . \mathrm{s}^{-1}\right)\end{array}$ \\
\hline 1 & $5.45 \pm 0.27 \mathrm{Cd}$ & $67.24 \pm 3.23 \mathrm{Fe}$ & $292.02 \pm 11.03 \mathrm{De}$ & $0.83 \pm 0.01 \mathrm{Ee}$ \\
\hline 2 & $6.40 \pm 0.25 \mathrm{ABb}$ & $109.10 \pm 4.12 \mathrm{Bb}$ & $345.65 \pm 12.18 \mathrm{ABabc}$ & $1.50 \pm 0.02 \mathrm{ABab}$ \\
\hline 3 & $6.01 \pm 0.26 \mathrm{BCbcd}$ & $89.16 \pm 2.74 \mathrm{DEcd}$ & $320.82 \pm 10.00 \mathrm{ABCDcde}$ & $1.26 \pm 0.02 \mathrm{CDd}$ \\
\hline 4 & $5.63 \pm 0.22 \mathrm{BCcd}$ & $70.21 \pm 4.51 \mathrm{Fe}$ & $298.71 \pm 13.41 \mathrm{CDde}$ & $0.90 \pm 0.02 \mathrm{Ee}$ \\
\hline 5 & $6.33 \pm 0.31 \mathrm{ABb}$ & $105.37 \pm 3.09 \mathrm{BCb}$ & $339.01 \pm 12.91 \mathrm{ABCabc}$ & $1.50 \pm 0.03 \mathrm{ABab}$ \\
\hline 6 & $6.15 \pm 0.13 \mathrm{BCbc}$ & $96.09 \pm 4.17 \mathrm{CDc}$ & $325.12 \pm 10.63 \mathrm{ABCDbcd}$ & $1.38 \pm 0.01 \mathrm{BCc}$ \\
\hline 7 & $5.87 \pm 0.21 \mathrm{BCbcd}$ & $84.16 \pm 4.22 \mathrm{Ed}$ & $319.22 \pm 13.29 \mathrm{BCDcde}$ & $1.21 \pm 0.02 \mathrm{Dd}$ \\
\hline 8 & $6.21 \pm 0.27 \mathrm{ABCb}$ & $105.82 \pm 5.80 \mathrm{BCb}$ & $336.73 \pm 12.55 \mathrm{ABCabc}$ & $1.40 \pm 0.02 \mathrm{BCbc}$ \\
\hline 9 & $6.42 \pm 0.22 \mathrm{ABb}$ & $125.00 \pm 4.15 \mathrm{Aa}$ & $352.77 \pm 10.53 \mathrm{ABab}$ & $1.60 \pm 0.02 \mathrm{Aa}$ \\
\hline 10 & $6.99 \pm 0.25 \mathrm{Aa}$ & $114.23 \pm 5.06 \mathrm{ABb}$ & $363.38 \pm 15.01 \mathrm{Aa}$ & $1.53 \pm 0.01 \mathrm{ABa}$ \\
\hline
\end{tabular}

Note: Data presented in the tale were mean values $\pm S D$ of three repetitions in the same treatments. Different capital letters indicated significance at $P<0.01$ level, small letters indicated significance at $P<0.05$ level. The same below.

\subsection{Effects of Different Fertilization Treatments on the Yield and Total Saponin Content of Pulsatilla Chinensis}

From table 3, compared with the control (treatment 1), the dry weights of the aerial parts and roots of Pulsatilla chinensis in each treatment increased to different degrees, and the differences were significant or extremely significant. Single application of nitrogen fertilizer, phosphorus fertilizer and potassium fertilizer significantly promoted the growth of aboveground parts, among which single application of nitrogen fertilizer promoted the most obvious effect, followed by potassium fertilizer, and finally single application of phosphorus fertilizer. the difference between the three reached significant level. Among the treatments of nitrogen fertilizer, phosphorus fertilizer and potassium fertilizer, the treatment of 9 aerial parts showed the most obvious effect of increasing yield, with $96.30 \%$ increase. In addition, single application of nitrogen fertilizer increased root weight as the most obvious, followed by phosphate fertilizer. Among the treatments of nitrogen fertilizer, phosphate fertilizer and potash fertilizer, the root weight of treatment 10 had the most obvious effect of increasing yield, with $67.86 \%$ increase.

The total saponin content of Pulsatilla root in each treatment was significantly higher than that of the control (treatment 1), and the total saponin content increased by $25.07 \%-64.36 \%$, and there was significant difference among the treatments. The yield increase effect of phosphate fertilizer alone on total saponin content is the most obvious, followed by nitrogen fertilizer and potassium fertilizer alone. The effect of nitrogen fertilizer, phosphate fertilizer and potassium fertilizer on the total saponin content in Pulsatilla chinensis was as follows: nitrogen-phosphorus combination > phosphorus-potassium combination > nitrogen-potassium combination. Among the treatments of nitrogen fertilizer, phosphate fertilizer and potash fertilizer, the yield increase is the most obvious among the treatments with 10 total saponin contents.

Table3. Biomass and total saponins contents of different fertilization in Pulsatilla chinensis ( $\bar{x} \pm s)$

\begin{tabular}{|c|c|c|c|c|}
\hline Number & $\begin{array}{c}\text { In Aerial parts / DW } \\
\text { (g/ each plant) }\end{array}$ & $\begin{array}{c}\text { Roots / DW } \\
\text { (g/ each plant) }\end{array}$ & Root-top ratio & $\begin{array}{c}\text { Total saponins } \\
(\mathrm{mg} / \mathrm{g})\end{array}$ \\
\hline 1 & $10.28 \pm 4.15 \mathrm{Ff}$ & $5.88 \pm 2.02 \mathrm{Ff}$ & $0.57 \pm 0.02 \mathrm{BCbc}$ & $42.17 \pm 1.21 \mathrm{Ef}$ \\
\hline 2 & $14.92 \pm 3.55 \mathrm{Dd}$ & $7.86 \pm 1.98 \mathrm{CEDcd}$ & $0.53 \pm 0.01 \mathrm{CDcd}$ & $55.42 \pm 0.92 \mathrm{CDde}$ \\
\hline
\end{tabular}


Effects of nitrogen, phosphorus and potassium fertilization on photosynthetic characteristics, yield and quality of Pulsatilla chinensis

\begin{tabular}{|c|c|c|c|c|}
\hline 3 & $12.05 \pm 4.31 \mathrm{EFe}$ & $7.21 \pm 2.31 \mathrm{Ede}$ & $0.60 \pm 0.01 \mathrm{ABb}$ & $57.89 \pm 0.61 \mathrm{CDcde}$ \\
\hline 4 & $12.85 \pm 3.85 \mathrm{Ee}$ & $8.39 \pm 1.02 \mathrm{BCDbc}$ & $0.65 \pm 0.03 \mathrm{Aa}$ & $52.96 \pm 1.31 \mathrm{De}$ \\
\hline 5 & $17.27 \pm 2.90 \mathrm{BCb}$ & $7.92 \pm 1.73 \mathrm{CDEcd}$ & $0.46 \pm 0.02 \mathrm{EFfg}$ & $60.12 \pm 1.73 \mathrm{BCDbcd}$ \\
\hline 6 & $15.55 \pm 3.66 \mathrm{CDcd}$ & $7.48 \pm 1.90 \mathrm{DEde}$ & $0.48 \pm 0.01 \mathrm{DEFef}$ & $52.74 \pm 0.88 \mathrm{De}$ \\
\hline 7 & $16.32 \pm 4.79 \mathrm{CDbcd}$ & $6.93 \pm 2.54 \mathrm{Ee}$ & $0.42 \pm 0.01 \mathrm{Fg}$ & $54.77 \pm 1.40 \mathrm{De}$ \\
\hline 8 & $16.77 \pm 2.68 \mathrm{CDbc}$ & $8.72 \pm 2.88 \mathrm{BCb}$ & $0.52 \pm 0.01 \mathrm{CDEde}$ & $62.33 \pm 1.02 \mathrm{ABCbc}$ \\
\hline 9 & $20.18 \pm 4.94 \mathrm{Aa}$ & $9.06 \pm 2.05 \mathrm{ABb}$ & $0.45 \pm 0.02 \mathrm{Ffg}$ & $65.20 \pm 0.89 \mathrm{ABab}$ \\
\hline 10 & $18.85 \pm 3.56 \mathrm{ABa}$ & $9.87 \pm 1.79 \mathrm{Aa}$ & $0.52 \pm 0.01 \mathrm{CDEde}$ & $69.31 \pm 1.07 \mathrm{Aa}$ \\
\hline
\end{tabular}

3.3. Corre lation Analysis Between Photosynthe tic Characte ristics, Quality and Yield ofPulsatilla Chinensis

As can be seen from table 4, there is no significant correlation between root removal dry weight and transpiration rate after different nitrogen, phosphorus and potassium fertilization, and there is a significant or extremely significant positive correlation between photosynthetic parameters of Pulsatilla chinensis leaves and dry weight of aboveground parts, dry weight of roots and total saponin content, which indicates that the optimization of photosynthetic characteristics of Pulsatilla chinensis growth after nitrogen, phosphorus and potassium fertilization improves the yield and quality of Pulsatilla chinensis.

\section{DisCUSSION AND CONCLUSION}

\subsection{Effect of Nitrogen, Phos phorus and Potassium Fertilization on Photos ynthe tic Characteristics of Pulsatilla Chinensis}

Plant photosynthetic parameters to some extent reflect the growth of plants. Nitrogen, phosphorus and potassium have obvious effects on plant photosynthesis, especially phosphorus. proper phosphorus application can promote the transmission and phosphorylation of photosynthetic electrons, reduce quantum demand and increase net photosynthetic rate ${ }^{[8]}$. In this study, the photosynthetic parameters of Pulsatilla chinensis leaves showed high consistency and had high correlation with the yield and quality of Pulsatilla chinensis. it showed that fertilization could improve the effect of " metabolic source" of Pulsatilla chinensis leaves, produce more nutrients and finally store them in " metabolic pool", thus improving the yield and quality of Pulsatilla chinensis. In addition, in the formula fertilization of nitrogen, phosphorus and potassium, the single application of potassium fertilizer had little influence on photosynthetic parameters of Pulsatilla chinensis, which might be related to the higher concentration of available potassium in the soil of this test site (water network area of lixiahe plain).

\subsection{Effect of Nitrogen, Phosphorus and Potassium Fertilizer on Yield of Pulsatilla Chinensis}

In the research of nitrogen, phosphorus and potassium formula fertilization, the research on crop yield is the most concentrated field at present. through formula fertilization, the best fertilization scheme and the best yield can be found. The early balanced fertilization scheme mainly aims to maintain the original fertility level of soil and supplement the nutrient elements consumed by crops, while the modern balanced fertilization scheme develops in depth and diversity, aiming at obtaining larger yield (biomass) on the premise of not affecting the nutrient balance. The results showed that nitrogen fertilizer had the greatest influence on the aboveground part and root yield of Pulsatilla chinensis. phosphorus fertilizer had greater influence on the aboveground part yield than potassium fertilizer, while potassium fertilizer had greater influence on root yield than phosphorus fertilizer, which indicated that different parts of Pulsatilla chinensis had different requirements on fertilizer. nitrogen and phosphorus combined application might be more beneficial to photosynthesis and growth of aboveground part, while nitrogen and potassium combined application was more beneficial to dry matter accumulation of roots. Huang qiaoyi and other studies found that nitrogen fertilizer had the greatest influence on cassava biomass, followed by potassium fertilizer and phosphorus fertilizer ${ }^{[9]}$; Li hong and other studies found that nitrogen fertilizer had the greatest influence on bletilla striata yield, followed by phosphate fertilizer and potash fertilizer ${ }^{[10]}$, which might be related to different plant species, different research plant organs and different soil and environmental quality in the test site.

\subsection{Effects of Nitrogen, Phosphorus and Potassium Fertilizer on the Quality of Pulsatilla Chinensis}


Effects of nitrogen, phosphorus and potassium fertilization on photosynthetic characteristics, yield and quality of Pulsatilla chinensis

In the research of nitrogen, phosphorus and potassium fertilization, the quality of the final harvest products of crops has always been one of the important parameters of the research. The results of this study show that phosphate fertilizer has a great influence on the quality of Pulsatilla chinensis. phosphorus is the key factor to realize various functions in plant life, and it helps to store and transport energy. at the same time, it is also one of the main participants of biological substances such as phosphoric acid, phosphoprotein, phospholipid and phosphosugar ${ }^{[11]}$. Zhao kai et al studied the effects of nitrogen, phosphorus and potassium on onion yield and quality, and found that phosphate fertilizer had the greatest effect on onion quality, followed by nitrogen fertilizer and potassium fertilizer, which was similar to the results of this study ${ }^{[12]}$. To sum up, Pulsatilla chinensis is a nitrogen-loving plant, which requires a large amount of nitrogen fertilizer. phosphate fertilizer has a larger influence on photosynthetic characteristics, root growth and quality, and potassium fertilizer has a more obvious influence on the growth of aboveground parts. The precise fertilization research of medicinal plants should pay attention to the yield and the quantity of secondary metabolites at the same time. the balanced application of nitrogen, phosphorus and potassium has a good promoting effect on the yield and quality of Pulsatilla chinensis. considering the yield and quality comprehensively, the optimal fertilization scheme is $180 \mathrm{~kg} / \mathrm{hm}^{2}$ nitrogen, $225 \mathrm{~kg} / \mathrm{hm}^{2}$ phosphorus and $79.8 \mathrm{~kg} / \mathrm{hm}^{2}$ potassium, which is worthy of application and popularization.

\section{ACKNOWLEDGMENTS}

The authors are thankful to the Jiangsu Agri-animal Husbandry Vocational College for providing infrastructural facility and financial support (Grant NO: NSF201511-2; Grant NO: NSFPT201627). We would like to thank the associate professor Xiaojiang Chen's revision.

\section{REFERENCES}

[1] Gao Baoning, Jiang Xinke, Wei Limin. Medicinal ornamental wild plant -- Pulsatilla chinensis. Forest byProduct and Speciality in China, 2011,3:72-73.

[2] Yang Fengkun, Li Cheng Ying, Wu Lianyong. Research progress of Pulsatilla chinensis. Chinese Journal of veterinary medicine, 2011,2:23-24.

[3] Ding Xiujuan, Chen Chong, Li Xia, et al. Chemical constituents of Pulsatilla chinensis. Chinese Traditional and Herbal Drugs, 2010,41 (12): 1952-1954.

[4] Pan Xin society, Zhang Hongli, Han Chongxuan, et al. Research status and Prospect of bioactivity of Pulsatilla chinensis. Acta Agriculturae Boreali-Occidentalis Sinica, 2014,13 (4): 160-164.

[5] Zhang Zixue, Ding Wei, Tang Yong, et al. Tissue culture of Pulsatilla chinensis. China J Chin Mater Med, 2004,29 (3): 215-218.

[6] Wei Jing, Zhang Zixue, Yu Qun, et al. Germination characteristics of Pulsatilla chinensis seeds.Seeds, 2005,24 (4): 60-62.

[7] Li Haiyan, Hao Ning, Xu Yongnan, et al. Optimization of extraction technology of total saponins from Pulsatilla cernua. Journal of Chinese Medicinal Materials, 2010,33 (4): 617-620.

[8] Krause G H, Wei E. Chlorophyll fluorescence and photosynthesis: The basis. Annual Review of Plant Physiology and Plant Molecular Biology,1991,42:313-349.

[9] Huang Qiaoyi, Tang Shuanhu, Chen Jiansheng, et al. Effects of different N, P and K treatments on absorption and accumulation of nutrients and yield of cassava. Plant Nutrition and Fertilizer Science, 2014, 20 (4): 947 956.

[10] Li Jiaohong, Zhang Chongyu, Luo Guangqiong. Effect of fertilizer application of nitrogen, phosphorus, and potassium on output and polysaccharides in Bletilla striata. Chinese Traditional And Herbal Drugs, 2009,40 (11): 1803-1805.

[11] Hu Du Jing, Dong Wuzhi, Ge Dan Zhi. Theory and practice of potassium nutrition in plants [M]. Changsha, China: Hunan science and Technology Press, 1993:10-20.

[12] Zhao Kai, Li Jin, Xu Ning, XU Kun. The effects of combined application of N、P and K on the yield and quality of onion. Plant Nutrition and Fertilizer Science, 2008,14 (3): 558-563.

Citation: WEI Qing-cui \& LI Cheng-zhong, "Effects of nitrogen, phosphorus and potassium fertilization on photosynthetic characteristics, yield and quality of Pulsatilla chinensis, International Journal of Forestry and Horticulture, vol. 4, no. 2, p. 44-48, 2018. http://dx.doi.org/10.20431/2454-9487.0402006

Copyright: (C) 2018 WEI Qing-cui \& LI Cheng-zhong. This is an open-access article distributed under the terms of the Creative Commons Attribution License, which permits unrestricted use, distribution, and reproduction in any medium, provided the original author and source are credited. 